\title{
Imposto Inflacionário e Transferências Inflacionárias no Mercosul e nos Estados Unidos
}

- Rubens Penha CYSNE*

- PAUlo C. COIMBRA-LISBOA **

\section{RESUMO}

Este artigo apresenta as séries de imposto inflacionário (II), transferências inflacionárias para os bancos comerciais $(\mathrm{TI})$ e transferências inflacionárias totais $(T I T=I I+T I)$ para os países do Mercosul e para os Estados Unidos, no período que vai de 1989 a 2003.

\section{PalavRAS-CHAVE}

imposto inflacionário, inflação, bancos, transferências inflacionárias, Mercosul, Brasil

\section{ABSTRACT}

This work presents the series of inflation tax (II), inflation transfers to the comercial banks (TI) and total inflation transfers $(T I T=I I+T I)$ of the Mercosul countries and of the United States between 1989 and 2003.

\section{KEY WORDS}

inflation tax, inflation, banks, inflation transfers, Mercosul, Brasil

JEL CLASSIFICATION

E39, E59

\footnotetext{
* Professor da EPGE/FGV. E-mail: rubens@fgv.br; home-page: http://www2.fgv.br/professor/rubens/. End. para contato: Escola de Pós-Graduação em Economia da Fundação Getulio Vargas, Praia de Botafogo I 90, I I 00, Rio de Janeiro, RJ, Brasil, CEP: 22250-900.

** Doutorando em Economia da EPGE/FGV. E-mail I: pc.coimbra@gmail.com; e-mail 2: coimbra@fgvmail.br; homepage: http://www2.fgv.br/aluno/coimbra/

(Recebido em março de 2005. Aceito para publicação em agosto de 2006).
} 


\section{INTRODUÇÃO}

Em um país com inflação positiva, define-se imposto inflacionário (II) como os juros reais negativos pagos pelo Banco Central sobre seu passivo monetário (composto pelo papel-moeda em poder do público e pelos encaixes totais dos bancos comerciais ${ }^{\mathrm{l}}$ ), e como transferência inflacionária (TI) o juro real negativo pago pela diferença entre os depósitos a vista e os encaixes totais dos bancos comerciais ou, equivalentemente, entre os meios de pagamento e a base monetária.

Consolidando-se o balanço do Banco Central ao balanço consolidado dos bancos comerciais, chega-se ao balanço do sistema bancário (ou sistema monetário). Nesta consolidação, os encaixes totais dos bancos comerciais, que se constituem em conta de ativo dos bancos comerciais e de passivo do Banco Central, anulam-se mutuamente. Isto posto, o passivo monetário do sistema bancário como um todo passa a ser dado pela soma do papel-moeda em poder do público mais os depósitos a vista dos bancos comerciais, ou seja, pelos meios de pagamento, Ml.

Logo, a soma do imposto inflacionário e das transferências inflacionárias equivale aos juros reais negativos sobre Ml pagos pelo sistema bancário (Banco Central e bancos comerciais) como um todo para o restante da economia. A este total dá-se o nome de transferências inflacionárias totais $(\mathrm{TIT}=\mathrm{II}+\mathrm{TI}$ ), as quais representam as transferências compulsórias de renda, em razão da existência de inflação, a favor do sistema bancário emissor de Ml, e contra o restante da(s) economia(s) que mantém Mi entre seus ativos, pessoas físicas e jurídicas residentes no país, em particular.

As transferências arbitrárias de renda aqui mencionadas nada tem a ver com o fato de os salários acompanharem ou não a inflação. Elas são perdas sistemáticas de renda decorrentes da manutenção de ativos que pagam juros nominais nulos em um ambiente de inflação estritamente positiva. Tais transferências só deixariam de existir se não houvesse meios de pagamento emitidos pelo sistema bancário e de posse do setor não bancário, se estes meios de pagamento fossem indexados à inflação, ou se a inflação fosse nula.

Também não se deve interpretar tais transferências como "lucros dos bancos com o processo inflacionário". Isto porque a análise contempla apenas os efeitos da inflação sobre ativos e passivos (das instituições financeiras bancárias) que, por definição, rendem juros nominais nulos, e não sobre o balanço patrimonial como um todo, ou mesmo sobre o resultado das operações correntes dos bancos. Nos períodos de infla-

1 Na definição adotada aqui, tanto depósitos a vista quanto encaixes totais pagam juros nominais nulos. Os encaixes totais compõem-se dos encaixes voluntários em moeda e dos encaixes compulsórios (em moeda ou em depósitos não remunerados no Banco Central) mantidos pelas instituições bancárias. 
ção elevada, por exemplo, as tarifas de serviços bancários costumam ser mais baixas do que nos períodos de inflação mais baixa, em parte devido aos maiores ganhos de floating com os depósitos a vista auferidos pelos bancos comerciais. Este exemplo ilustra a longa distância que separa o efeito global da inflação sobre o lucro dos bancos e as transferências aqui calculadas.

\section{- Relevância Macroeconômica}

As transferências inflacionárias são importantes variáveis do ponto de vista macroeconômico. Na análise aqui efetuada, há interesse tanto do ponto de vista em cross-section, comparando-se os vários países em um determinado ano ou período, quanto para um mesmo país, da perspectiva da evolução temporal.

No caso do imposto inflacionário, devido à importância que esta variável adquiriu, principalmente até meados da década de 1990, no financiamento residual dos déficits do setor público.

Quando alguns autores consideram, por exemplo, a possibilidade de implantação de uma moeda única para um conjunto de países, o Mercosul em particular (como, e.g., em Giambiagi e Rubini, 2003; Giambiagi, 1999; Ribeiro, 1999; e Giambiagi, 1997), cabe analisar os diferentes graus de dependência de cada uma das economias consideradas com relação ao imposto inflacionário. Isto porque, após a unificação monetária, tal receita deixa de ser uma variável (indiretamente) manipulável via Banco Central de cada país, posto que estes abdicam deste grau de liberdade. Neste sentido, os números apresentados neste trabalho podem ser de grande utilidade.

Cabe também destacar a relevância das transferências inflacionárias totais como uma medição direta dos custos de bem-estar da inflação quando se admite que a função de transação do tipo $\mathrm{F}(\mathrm{m} ; \mathrm{x} ; \mathrm{s})=\mathrm{G}(\mathrm{m} ; \mathrm{x}) \mathrm{s}$, em que $\mathrm{m}$ representa os encaixes reais dos meios de pagamento, $\mathrm{x}$ o mesmo, mas com relação a uma moeda remunerada, e $\mathrm{s}$ o custo de bem-estar da inflação, aqui igual ao shopping time. A demonstração inicial deste fato, quando $\mathrm{x}=0$, pode ser encontrada no manuscrito Lucas (1993, p. 14, eq. 4.14) e também na página 266 da versão publicada, na Econometrica, deste mesmo manuscrito (Lucas, 2000, p. 266). A demonstração mais geral de que as transferências inflacionárias coincidem com o custo de bem-estar da inflação, ${ }^{2}$ para o caso em que $\mathrm{x}$ $\neq 0$, é apresentada em Simonsen e Cysne (2001) e, com uma discussão mais explícita, em Cysne, Maldonado e Monteiro (2005).

2 Os custos de bem-estar da inflação, no caso desta tecnologia transacional, coincidem com o imposto inflacionário quando se utiliza a base monetária na mensuração, e com as transferências inflacionárias totais, quando se utilizam os meios de pagamento na mensuração dos mesmos. Para uma discussão sobre qual agregado monetário deve ser utilizado no caso ótimo, ver Cysne (2003). 


\section{ASPECTOS METODOLÓGICOS}

Se B e P representam, respectivamente, a base monetária e o nível de preços em função do tempo, o imposto inflacionário entre os instantes de referência 0 e 1 , em moeda de poder aquisitivo do instante $j$, dá-se por:

$$
I I_{j}=P_{j} \int_{0}^{1} \frac{B}{P^{2}} \frac{d P}{d t} d t
$$

Para o cálculo das transferências inflacionárias para os bancos comerciais (TI) substitui-se, em (1), B por $\mathrm{Ml}_{1}-\mathrm{B}$. No caso das transferências inflacionárias totais (TIT) troca-se B por Mi. Tem-se, assim, que TIT = II+TI.

Como não se dispõe das funções $\mathrm{B}(\mathrm{t}), \mathrm{Ml}(\mathrm{t})$ e $\mathrm{P}(\mathrm{t})$ em tempo contínuo, para fins práticos aproxima-se (l) por somatórios. Quando se passa de integrais para somatórios, existem incontáveis metodologias por meio das quais tal cálculo pode ser efetuado, todas necessariamente arbitrárias e aproximadas.

A metodologia que utilizamos aqui para o cálculo dos juros reais negativos, respectivamente, sobre a base monetária, sobre a diferença entre os meios de pagamento e a base monetária e, por último, sobre os meios de pagamento, pode ser obtida em Cysne (1990) ou em Simonsen e Cysne (1995, capítulo 3). Cysne e Coimbra-Lisboa (2004) usam esta mesma metodologia para atualizar a série histórica de imposto inflacionário e de transferências inflacionárias para o Brasil inicialmente publicada em Cysne (1994).

Em virtude de a moeda pagar juros nominais nulos, a taxa de juros real (negativa quando a inflação é estritamente positiva) paga pela moeda entre os períodos t e t + l é expressa como:

$$
r_{t+1}=\frac{P_{t}-P_{t+1}}{P_{t+1}}
$$

Seja At o saldo do agregado monetário A no mês t. Uma forma possível de se calcular os juros reais (negativos) Jt pagos por A, denominados em moeda corrente, é dada por:

$$
J_{t}=A_{t} \frac{P_{t}-P_{t+1}}{P_{t+1}}
$$

As transferências contra os detentores de agregados monetários, por definição, equivalem ao simétrico aditivo dos juros reais pagos pelo agregado. Isto posto, para o cálculo de II, TI e TIT utilizamos -Jt, em que Jté calculado por (2). Observações técnicas sobre a metodologia de cálculo (2) são apresentadas posteriormente neste texto. Para expressar os valores como porcentual do PIB procede-se ao somatório de Jt com t variando de 1 a 
12 (Janeiro a Dezembro de cada ano) e divide-se pelo PIB anual. Têm-se, assim, valores em unidades correntes do ano no numerador e no denominador.

Tal como no caso contínuo antes mencionado, na avaliação de Jt o agregado monetário A assume os valores de $\mathrm{B}$ quando se trata de II, de $\mathrm{Ml}-\mathrm{B}$ no cálculo de TI e de $\mathrm{Ml}$ no cálculo de TIT.

\section{ESTIMATIVAS EMPÍRICAS}

A Tabela 1 apresenta a inflação anual e a evolução das transferências inflacionárias de 1989 a 2003, para os países do Mercosul e para os Estados Unidos. Os cálculos para os Estados Unidos são efetuados visando estabelecer uma comparação com os demais países do Mercosul. Os dados para o Brasil reproduzem parte da série que consta em Cysne e Coimbra-Lisboa (2004).

TABELA I - IMPOSTO INFLACIONÁRIO (II), TRANSFERÊNCIAS INFLACIONÁRIAS PARA OS BANCOS COMERCIAIS (TI) E TRANSFERENCIAS TOTAIS (TIT = II + TI) COMO PORCENTAGEM DO PRODUTO INTERNO BRUTO (PIB)

\begin{tabular}{llrrrrr}
\hline & & Brasil & Argentina & Uruguai & Paraguai & EUA \\
\hline 1989 & Inflação & $1.782,90$ & $4.923,32$ & 89,18 & 28,53 & 4,65 \\
& II / PIB & 4,35 & 5,02 & 1,66 & 1,14 & 0,20 \\
& TI / PIB & 2,36 & 2,84 & 1,23 & 0,79 & 0,52 \\
& TIT / PIB & 6,70 & 7,86 & 2,89 & 1,93 & 0,72 \\
\hline 1990 & Inflação & $1.476,56$ & $1.343,92$ & 128,95 & 43,11 & 6,11 \\
& II / PIB & 3,39 & 1,71 & 1,93 & 1,30 & 0,23 \\
& TI / PIB & 1,89 & 0,76 & 1,52 & 1,00 & 0,54 \\
& TIT / PIB & 5,28 & 2,46 & 3,45 & 2,29 & 0,77 \\
\hline 1991 & Inflação & 480,18 & 83,99 & 81,45 & 11,83 & 3,06 \\
& II / PIB & 3,08 & 0,76 & 1,36 & 0,46 & 0,11 \\
& TI / PIB & 2,11 & 0,36 & 0,96 & 0,30 & 0,25 \\
& TIT / PIB & 5,20 & 1,12 & 2,32 & 0,76 & 0,37 \\
\hline 1992 & Inflação & $1.157,94$ & 17,55 & 58,91 & 17,78 & 2,90 \\
& II / PIB & 2,69 & 0,34 & 1,14 & 0,66 & 0,14 \\
& TI / PIB & 1,90 & 0,20 & 0,91 & 0,43 & 0,34 \\
& TIT / PIB & 4,59 & 0,54 & 2,06 & 1,09 & 0,49 \\
\hline 1993 & Inflação & $2.709,38$ & 7,36 & 52,88 & 20,37 & 2,75 \\
& II / PIB & 2,91 & 0,19 & 1,13 & 0,77 & 0,12 \\
& TI / PIB & 1,99 & 0,12 & 1,04 & 0,45 & 0,29 \\
& TIT / PIB & 4,90 & 0,31 & 2,17 & 1,22 & 0,40 \\
\hline 1994 & Inflação & $1.090,21$ & 3,85 & 44,09 & 18,31 & 2,67 \\
& II / PIB & 1,01 & 0,18 & 0,98 & 0,61 & 0,13 \\
& TI / PIB & 0,56 & 0,10 & 1,01 & 0,40 & 0,31 \\
& TIT / PIB & 1,57 & 0,28 & 1,99 & 1,01 & 0,45 \\
\hline \multirow{6}{*}{19} & & & & & $($ continua) \\
& I. & & & & &
\end{tabular}




\begin{tabular}{|c|c|c|c|c|c|c|}
\hline & & Brasil & Argentina & Uruguai & Paraguai & EUA \\
\hline \multirow[t]{4}{*}{1995} & Inflação & 14,95 & 1,61 & 35,44 & 10,53 & 2,54 \\
\hline & II / PIB & 0,34 & 0,03 & 0,77 & 0,41 & 0,13 \\
\hline & TI/ PIB & 0,07 & 0,01 & 0,78 & 0,29 & 0,28 \\
\hline & TIT / PIB & 0,41 & 0,04 & 1,55 & 0,69 & 0,42 \\
\hline \multirow[t]{4}{*}{1996} & Inflação & 9,76 & 0,05 & 24,33 & 8,18 & 3,32 \\
\hline & II / PIB & 0,21 & 0,01 & 0,54 & 0,28 & 0,15 \\
\hline & TI/PIB & 0,08 & 0,01 & 0,59 & 0,21 & 0,28 \\
\hline & TIT / PIB & 0,29 & 0,02 & 1,14 & 0,49 & 0,42 \\
\hline \multirow[t]{4}{*}{1997} & Inflação & 7,41 & 0,33 & 15,17 & 6,20 & 1,70 \\
\hline & II / PIB & 0,19 & 0,02 & 0,33 & 0,27 & 0,08 \\
\hline & TI/PIB & 0,09 & 0,02 & 0,38 & 0,18 & 0,12 \\
\hline & TIT / PIB & 0,28 & 0,04 & 0,71 & 0,45 & 0,20 \\
\hline \multirow[t]{4}{*}{1998} & Inflação & 1,38 & 0,67 & 8,63 & 14,64 & 1,61 \\
\hline & II / PIB & 0,08 & 0,02 & 0,19 & 0,54 & 0,08 \\
\hline & $\mathrm{TI} / \mathrm{PIB}$ & 0,02 & 0,02 & 0,22 & 0,31 & 0,12 \\
\hline & TIT / PIB & 0,10 & 0,04 & 0,41 & 0,85 & 0,20 \\
\hline \multirow[t]{4}{*}{1999} & Inflação & 20,41 & $-1,82$ & 4,17 & 5,40 & 2,68 \\
\hline & II / PIB & 0,70 & $-0,06$ & 0,10 & 0,27 & 0,14 \\
\hline & $\mathrm{TI} / \mathrm{PIB}$ & 0,18 & $-0,03$ & 0,12 & 0,15 & 0,18 \\
\hline & TIT / PIB & 0,87 & $-0,09$ & 0,21 & 0,42 & 0,32 \\
\hline \multirow[t]{4}{*}{2000} & Inflação & 9,60 & \begin{tabular}{|l|}
$-0,73$ \\
\end{tabular} & 5,05 & 8,64 & 3,39 \\
\hline & II / PIB & 0,32 & $-0,06$ & 0,12 & 0,35 & 0,19 \\
\hline & $\mathrm{TI} / \mathrm{PIB}$ & 0,15 & $-0,04$ & 0,14 & 0,24 & 0,22 \\
\hline & TIT / PIB & 0,47 & $-0,10$ & 0,26 & 0,59 & 0,41 \\
\hline \multirow[t]{4}{*}{2001} & Inflação & 10,31 & $-1,54$ & 3,59 & 8,38 & 1,55 \\
\hline & II / PIB & 0,36 & 0,02 & 0,11 & 0,29 & 0,06 \\
\hline & TI/PIB & 0,19 & 0,02 & 0,11 & 0,29 & 0,06 \\
\hline & TIT / PIB & 0,55 & 0,03 & 0,22 & 0,58 & 0,12 \\
\hline \multirow[t]{4}{*}{2002} & Inflação & 26,64 & 40,95 & 25,98 & 14,65 & 2,38 \\
\hline & II / PIB & 1,06 & 1,30 & 0,57 & 0,63 & 0,15 \\
\hline & TI/PIB & 0,53 & 1,14 & 0,56 & 0,59 & 0,14 \\
\hline & TIT / PIB & 1,59 & 2,44 & 1,13 & 1,22 & 0,29 \\
\hline \multirow[t]{4}{*}{2003} & Inflação & 7,38 & 3,66 & 10,15 & 9,32 & 1,88 \\
\hline & II / PIB & 0,29 & 0,15 & 0,24 & 0,22 & 0,11 \\
\hline & TI/ PIB & 0,13 & 0,10 & 0,26 & 0,24 & 0,11 \\
\hline & TIT / PIB & 0,42 & 0,25 & 0,51 & 0,46 & 0,22 \\
\hline Média & Inflação & $1.291,02$ & 247,11 & 73,75 & 22,92 & 3,68 \\
\hline \multirow[t]{3}{*}{$1989-1994$} & II / PIB & 2,91 & 1,37 & 1,37 & 0,82 & 0,16 \\
\hline & TI/PIB & 1,80 & 0,73 & 1,11 & 0,56 & 0,38 \\
\hline & TIT / PIB & 4,71 & 2,10 & 2,48 & 1,38 & 0,53 \\
\hline Média & Inflação & 11,76 & 4,13 & 14,24 & 9,51 & 2,34 \\
\hline \multirow[t]{3}{*}{$1995-2003$} & II / PIB & 0,39 & 0,16 & 0,33 & 0,36 & 0,12 \\
\hline & TI/ PIB & 0,16 & 0,14 & 0,35 & 0,28 & 0,17 \\
\hline & TIT / PIB & 0,55 & 0,30 & 0,68 & 0,64 & 0,29 \\
\hline Média & Inflação & 206,41 & 68,55 & 35,10 & 14,69 & 2,87 \\
\hline \multirow[t]{3}{*}{$1989-2003$} & II / PIB & 1,40 & 0,64 & 0,75 & 0,55 & 0,14 \\
\hline & TI/PIB & 0,82 & 0,37 & 0,66 & 0,39 & 0,25 \\
\hline & TIT / PIB & 2,21 & 1,02 & 1,40 & 0,94 & 0,39 \\
\hline
\end{tabular}

Fontes: Brasil - Cysne e Coimbra-Lisboa (2004).

Demais países - fonte primária de dados - International Financial Statistics (2004). 


\subsection{Observações Técnicas:}

a) Os detalhes técnicos relativos às séries de imposto inflacionário, transferências inflacionárias e transferências inflacionárias totais do Brasil são discutidos em Cysne e Coimbra-Lisboa (2004). Todos os dados referentes ao Brasil foram obtidos diretamente do Banco Central do Brasil e/ou do banco de dados da FGV (Projeto Aries) e repetem os dados utilizados em Cysne e Coimbra-Lisboa (2004). Os dados utilizados no trabalho têm periodicidade mensal.

b) Os dados relativos à base monetária, meios de pagamento, PIB e índice de preços, para os demais países do Mercosul que não o Brasil, bem como para os Estados Unidos, foram extraídos da publicação mensal do Fundo Monetário Internacional "International Financial Statistics" (IFS).

c) Os dados referentes aos agregados monetários são divulgados pelo IFS em moeda de final de período.

d) No que diz respeito ao conceito de base monetária, a série utilizada para o Brasil, que coincide com a série divulgada pelo Banco Central, foi a série IFS "19ma". Esta série, entretanto, não se estende a todos os países. Para os demais países da amostra, utilizamos a série " $14 a$ " do IFS, que corresponde ao papel-moeda em circulação nas estatísticas referentes ao Brasil. Isto posto, apenas nas comparações em cross-section com o Brasil, o imposto inflacionário dos demais países tende a ser mais baixo, e as transferências inflacionárias mais elevadas. As transferências inflacionárias totais não são afetadas por este fato.

e) No tocante aos meios de pagamento, utilizamos a série país-específica " $59 \mathrm{ma}$ " do IFS, referida como Ml no IFS, para os países do Mercosul (incluindo o Brasil e excluindo a Argentina) e para os Estados Unidos. No caso da Argentina, não se dispunha deste dado na série do IFS, por isto utilizamos a série " 34 ” do IFS, também denominada Ml, mas pertencente a um outro conjunto de dados do IFS.

f) O PIB dos demais países do Mercosul que não o Brasil foi extraído da série "99b" do IFS. No que se refere aos Estados Unidos, foi utilizada a série dessazonalizada do PIB, "99b.c" do IFS.

g) Para o cálculo da inflação e dos juros reais negativos pagos pelos agregados monetários dos demais países do Mercosul (que não o Brasil) e dos Estados Unidos utilizamos o índice de preços ao consumidor, IPC, apresentados na série "64" do IFS. No caso do Brasil foi utilizado o IGP-DI da FGV. 
h) Para o cálculo de Jt utilizamos a fórmula (2), que implica (assumindo coleta de preços entre o primeiro e último dia do mês) que o agregado monetário do mês té multiplicado pelo juro real (negativo) pago pela moeda, medido em termos centralizados, do dia 15 do mês $t$ ao dia 15 do mês $t+1$. Este procedimento é arbitrário e reflete apenas uma das várias alternativas possíveis. Como estamos mais interessados na evolução de longo prazo da série histórica do que nos valores específicos mês a mês, este ponto passa a ser de segunda ordem.

\subsection{Avaliação Comparativa dos Resultados}

a) Os valores negativos do imposto e das transferências inflacionárias calculadas para a Argentina em 1999 e 2000 devem-se às taxas de inflação mensais negativas registradas em alguns meses desses anos. Vale ressaltar que tal deflação é também capturada por outros índices de preços. Os dados para a Argentina registram também, em 2001, um período de deflação e imposto inflacionário positivo. Isto se dá porque o imposto inflacionário reportado aqui soma o produto das variações mensais dos preços pela base monetária, ao longo de todo o ano, e não o valor médio anual da base vezes a taxa de inflação anual. $\mathrm{O}$ mesmo, evidentemente, se aplica às transferências inflacionárias.

b) Entre 1989 e 2003 as transferências inflacionárias totais representaram, respectivamente, para o Brasil, Argentina, Uruguai, Paraguai e Estados Unidos, uma média, em termos de PIB de cada um dos respectivos países, de 2,21\%, 1,02\%, 1,40\%, $0,94 \%$ e $0,39 \%$. Grosso modo, em câmbio médio de 2003 , PIB de 2003 e dólares de 2003, isto significa que indivíduos e empresas nesses países transferiram em média, anualmente, para o setor bancário da economia, Bancos Centrais incluídos, em decorrência da inflação e do fato de os meios de pagamento pagarem juros nominais nulos, um poder de compra, respectivamente (para o Brasil, Argentina, Uruguai, Paraguai e Estados Unidos), da ordem de 10,89; 1,32; 0,16; 0,05 e 42,45 bilhões de dólares.

c) O Plano Real, em 1994, no Brasil, e o Plano Austral, em 1991, na Argentina, foram efetivos na redução da inflação nestes países. De um modo geral, podemos observar que a partir de 1995 as taxas de inflação dos países do Mercosul se situaram em patamares bastante inferiores em relação às taxas anteriormente verificadas. Por esta razão, incluímos na Tabela 1 uma média relativa ao período que vai de 1989 a 1994 e de 1995 a 2003, o que nos permite observar que as transferências inflacionárias totais passaram de $4,71 \%$ do PIB a $0,55 \%$ do PIB no Brasil, de $2,10 \%$ do PIB a $0,30 \%$ do PIB na Argentina, de $2,48 \%$ do PIB a $0,68 \%$ do PIB no Uruguai, de $1,38 \%$ do PIB a $0,64 \%$ do PIB no Paraguai, e de $0,53 \%$ do PIB a $0,29 \%$ do PIB nos Estados Unidos. 
d) Com exceção do Uruguai, entre 1995 e 2003 os maiores valores de TIT/PIB dos países do Mercosul ocorreram no ano de 2002 (no Uruguai isto se deu em 1995). Tais valores, em 2002, foram de 1,59\% do PIB no Brasil, 2,44\% do PIB na Argentina, $1,13 \%$ do PIB no Uruguai (com 1,55\% do PIB em 1995) e 1,22\% do PIB no Paraguai.

A Figura 1 apresenta a evolução, de 1995 a 2003, do imposto inflacionário como porcentual do PIB para cada um dos países do Mercosul e para os Estados Unidos.

FIGURA 1 - II/PIB: 1995-2003 - MERCOSUL E EUA

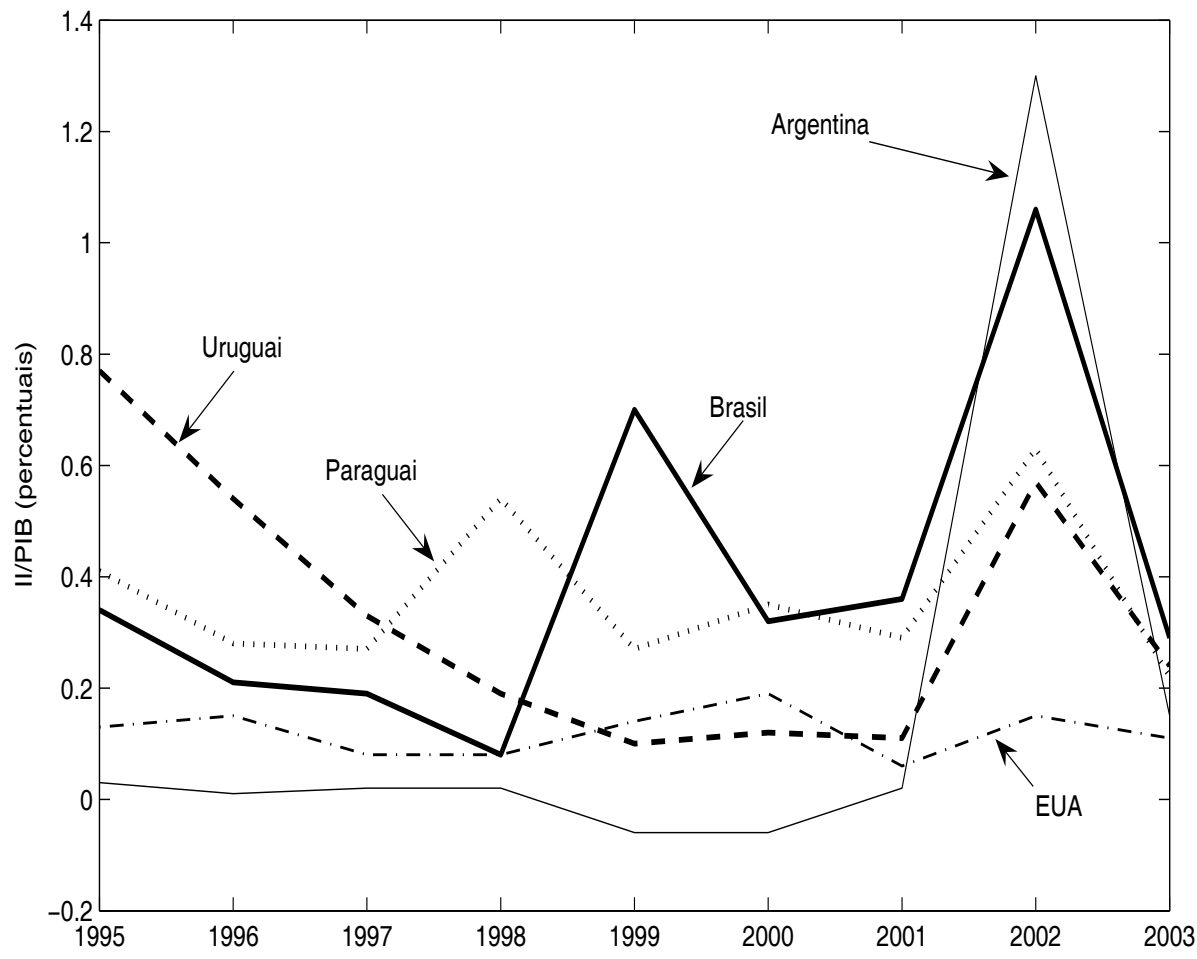

Uma primeira observação que decorre da Figura l é que para cada país pertencente ao Mercosul, tomado isoladamente, o maior valor do imposto inflacionário no período que vai de 1995 a 2003 é menor do que a média desta mesma variável entre 1989 e 1994. Isto reflete a queda dos níveis de inflação de tais países ocorrida a partir de 1995. A figura mostra também a consequiência altista, sobre o imposto inflacionário, decorrente da nova elevação de inflação ocorrida, grosso modo, a partir de 2001. Este ponto é particularmente marcante no caso da Argentina e, em segundo plano, do Brasil. A aceleração da inflação no Brasil deu-se notadamente em 2002, mas foi contida, em particular, pela utilização do sistema de metas de inflação. 
Como uma segunda observação, pode-se destacar a alta correlação no imposto inflacionário entre os diferentes países do Mercosul, notadamente no período que vai de 2001 a 2003. Tal correlação é facilmente percebida pela simples observação das séries.

A Figura 2 abaixo praticamente traduz o mesmo quadro descrito acima, desta vez, entretanto, com relação às transferências inflacionárias totais.

FIGURA 2 - TIT/PIB: 1995-2003 - MERCOSUL E EUA

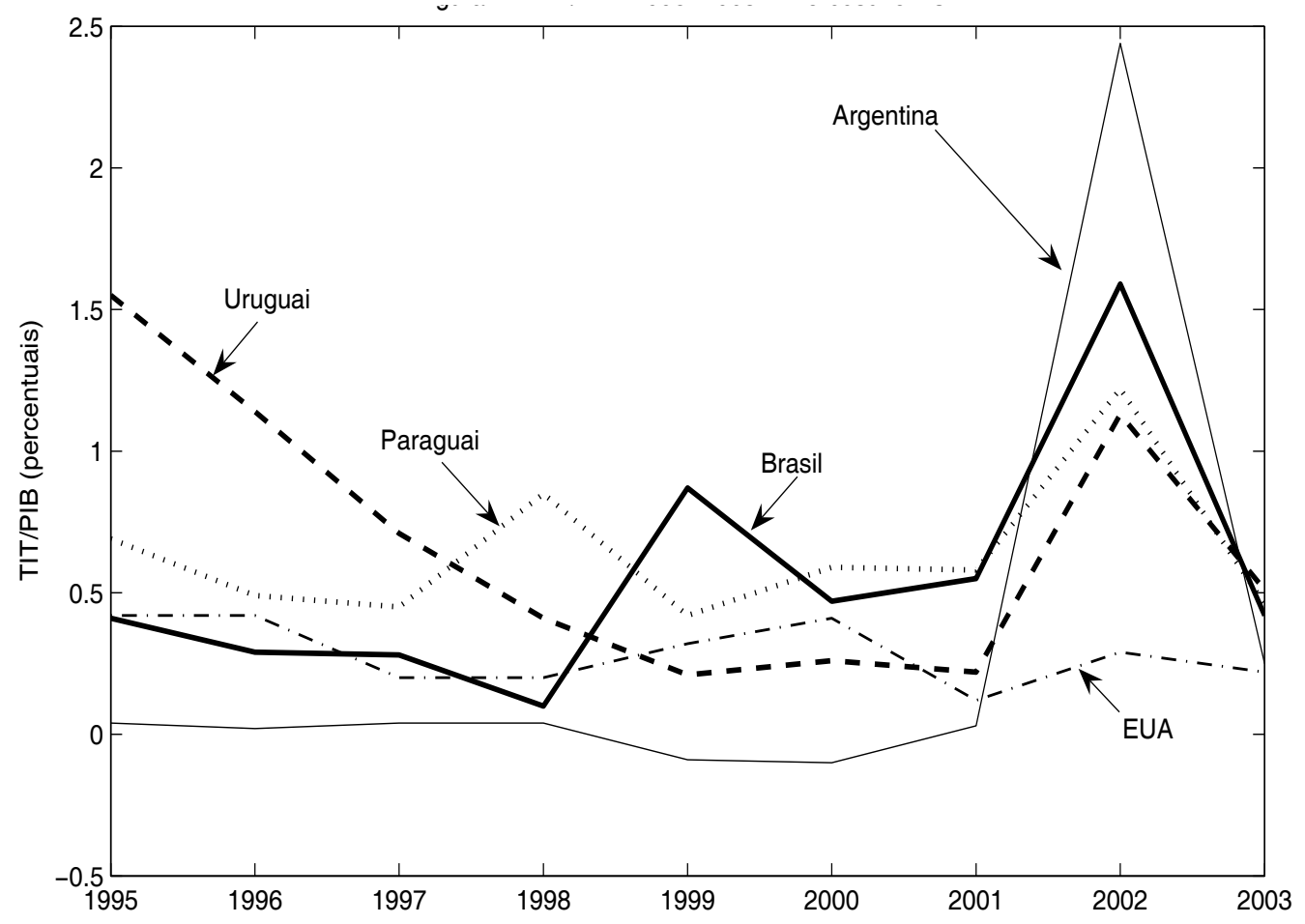

\subsection{Avaliação Pais a Pais:}

A Figura 3 trata do caso brasileiro.

Nota-se claramente que, a despeito das elevadíssimas taxas de inflação ocorridas entre 1988 e 1993 (todas elas superiores a 1.000\% a.a., exceto a de 1991, que foi de $480,2 \%)$, os mais altos valores para o Brasil, tanto do imposto inflacionário quanto das transferências inflacionárias totais se deram no ano de 1963 (respectivamente $5,40 \%$ do PIB e 9,03\% do PIB, para uma inflação de apenas $81,3 \%$ ). O fato de se ter 
valores tão elevados da relação entre transferências inflacionárias totais e a taxa de inflação, relativamente ao período que vai de 1988 a 1993, pode ser explicado pela demanda por moeda ser muito mais elevada em meados da década de 1960. De fato, nesta época não havia ainda substitutos tão próximos à moeda $\left(\mathrm{M}_{1}\right)$, como ocorre no período mais recente.

FIGURA 3 - BRASIL

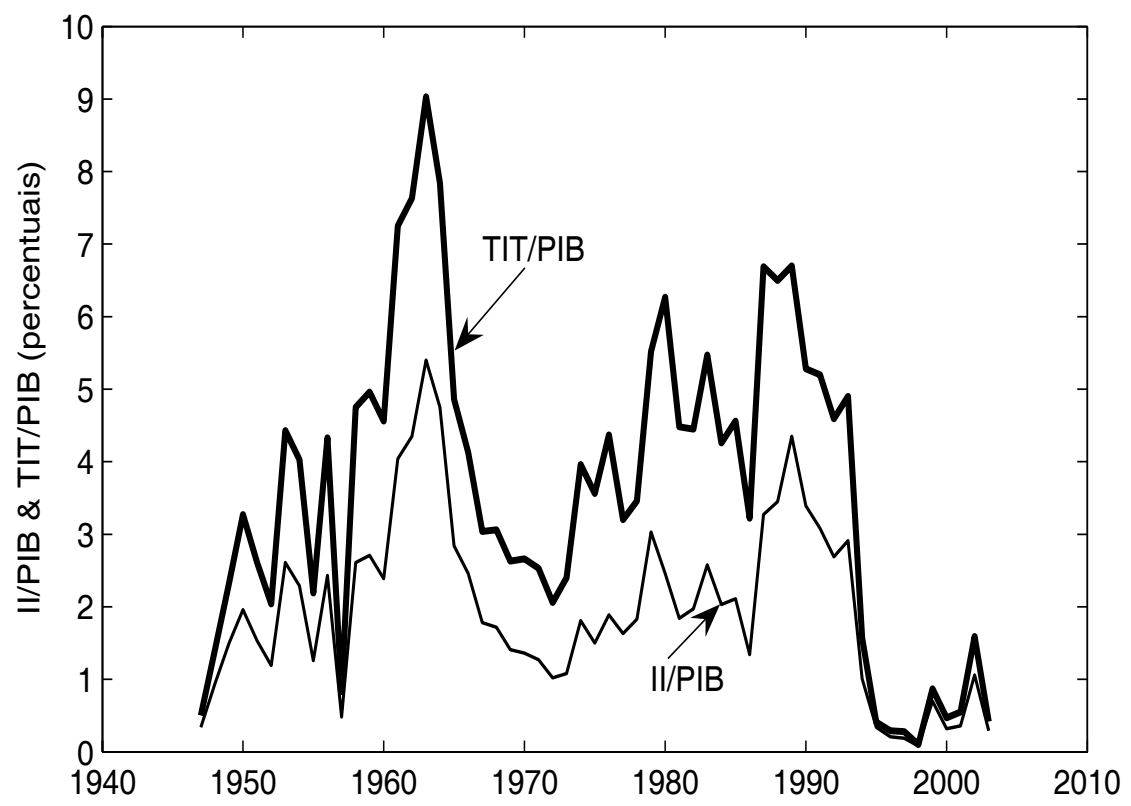

O reflexo do Plano Real sobre as transferências inflacionárias totais e o imposto inflacionário é marcante. Observa-se claramente a drástica redução destas variáveis a partir de meados de 1994.

A Figura 4 trata do caso argentino.

Observa-se no gráfico que, no caso da Argentina, os maiores valores do imposto inflacionário $(6,13 \%$ do PIB) e das transferências inflacionárias (15,26\% do PIB) ocorreram em 1975. Nesse ano, entretanto, a taxa de inflação anual, de 336,1\%, ficou bem abaixo das taxas anuais de $4.923 \%$ e $1.344 \%$ ocorridas, respectivamente, em 1989 e 1990. Este fenômeno traduz a queda da demanda por moeda ocorrida entre 1975 e 1989, em razão das inovações financeiras endogenamente criadas após o período de alta inflação em meados dos anos 1970. Caso semelhante, como visto acima, se deu também no Brasil. A inflação brasileira dos anos 1960, embora muito inferior 
àquela dos anos 1980 e 1990, gerou um imposto inflacionário como porcentual do PIB muito maior.

\section{FIGURA 4 - ARGENTINA}

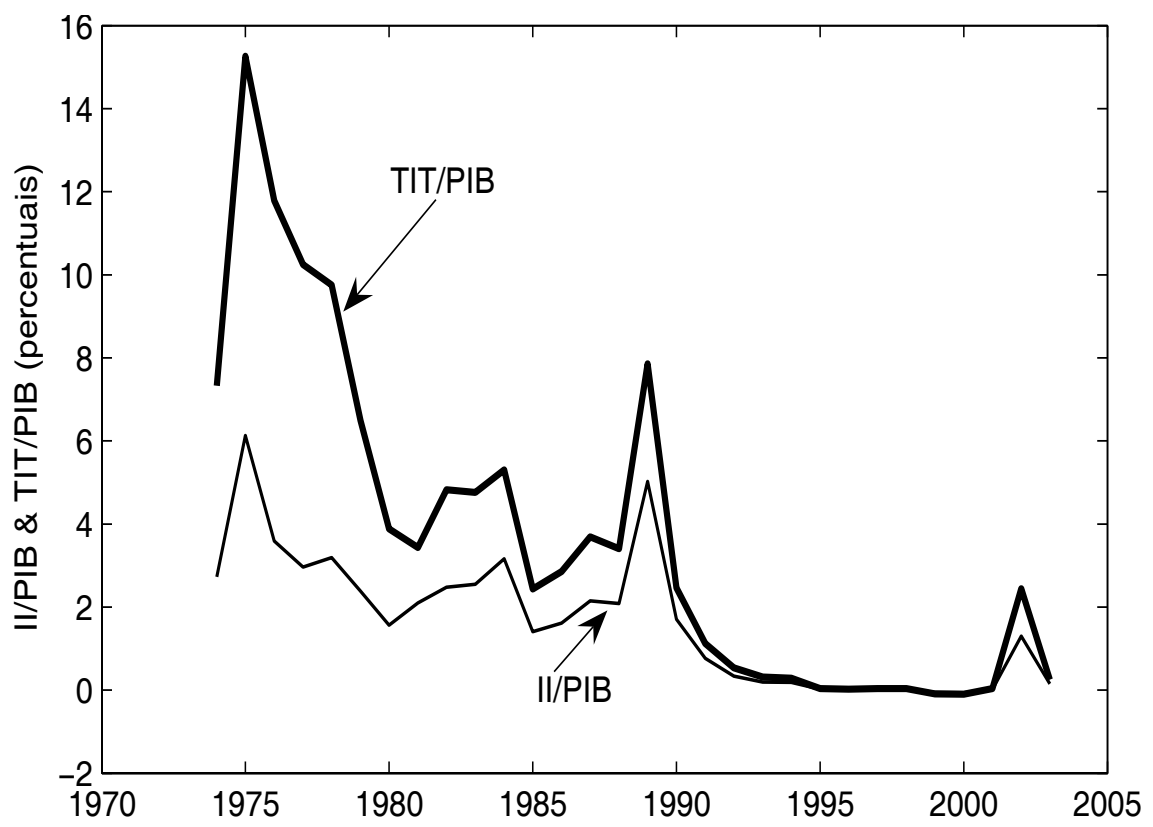

A alta inflação argentina de meados dos anos 1970 se deu durante o governo de María Estela Martínez, alcunhada de Isabelita. Nos anos de 1974 e 1975 a economia argentina sofreu sérios danos. As tentativas de estabilização implementadas pelo ministro Alfredo Gómez Morales em 1974 não lograram êxito, tendo provocado um complicado processo de estagflação. Em junho de 1975 o novo ministro de Economia, Celestino Rodrigo, promoveu uma forte desvalorização da moeda, acompanhada de aumentos de tarifas. A medida resultou em uma elevação da inflação, que passou de $40 \%$ ao ano em 1974 para $336,1 \%$ ao ano em 1975.

Ao final do ano de 2002, em virtude da crise de conversibilidade do peso em relação à moeda norte-americana, houve um severo recrudescimento inflacionário. Passou-se de uma deflação em 2001 para uma inflação de 41\% em 2002. A enorme fuga de capitais foi seguida de uma forte desvalorização da moeda argentina. Por causa da elevação da inflação, o imposto inflacionário passou de 0,018\% do PIB em 2001 para $1,30 \%$ do PIB em 2002.

A Figura 5 trata do caso do Uruguai. 


\section{FIGURA 5 - URUGUAI}

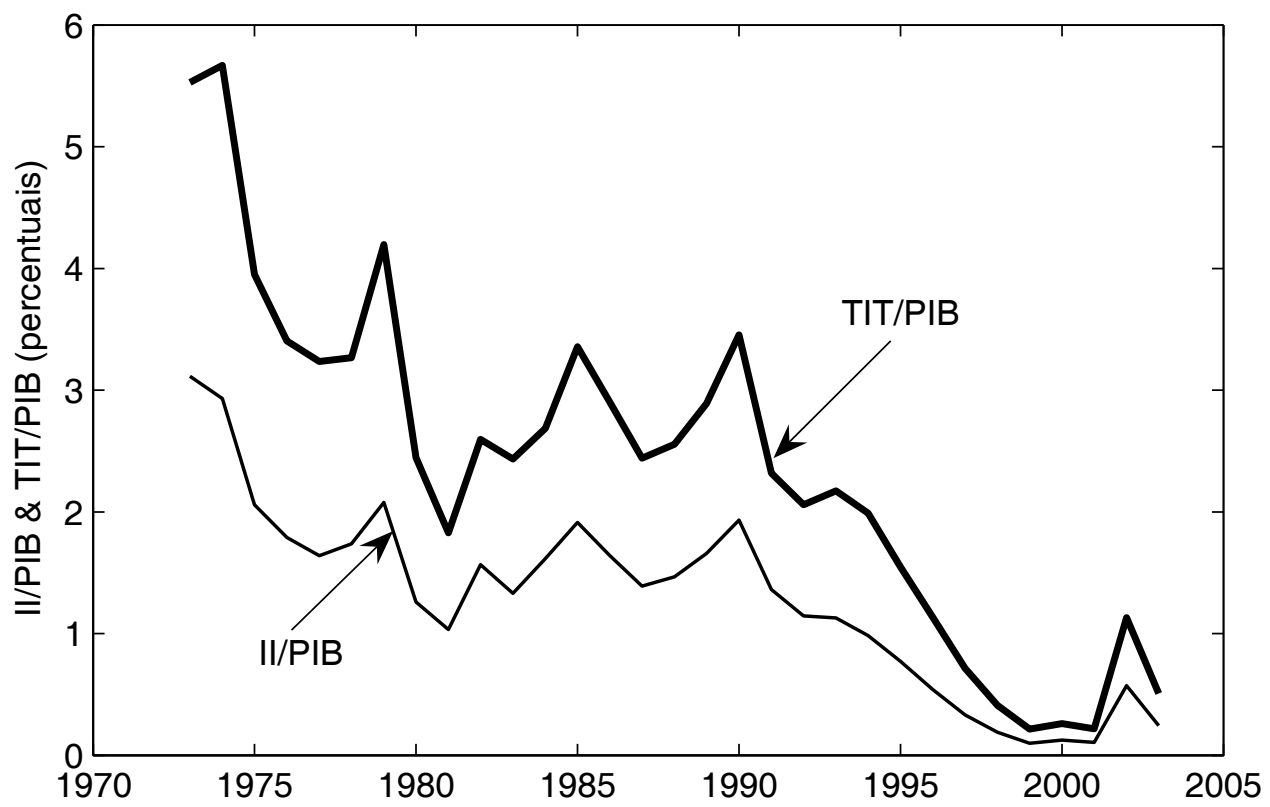

No período compreendido entre os anos 1973 e 2003 a inflação uruguaia superou os dois dígitos somente nos anos de 1974 e 1990 (registrando, respectivamente, 107,19\% a.a e $128,95 \%$ a.a.). No entanto, observa-se que as transferências inflacionárias totais foram bem mais elevadas em 1974 do que em 1990 (respectivamente 5,67\% do PIB e 3,45\% do PIB). A principal razão desta discrepância se deve à demanda por moeda mais elevada em 1974 do que em 1990 (em 1974 o agregado Ml correspondia a $11,63 \%$ do PIB, enquanto que em 1990 este agregado passou para 5,12\% do PIB).

Podemos também observar que há uma nítida tendência de queda, a partir de 1991, tanto do imposto inflacionário quanto das transferências inflacionárias totais, cujas médias anuais do período 1991 a 2003 (respectivamente $0,58 \%$ do PIB e 1,13\% do PIB) se situaram abaixo das menores taxas anuais destes agregados no período compreendido entre 1973 e 1990 . Vale ainda ressaltar que no ano de 2002 verificou-se um recrudescimento inflacionário (a taxa de inflação passou de 3,59\% a.a. em 2001 para $25,98 \%$ a.a. em 2002). O imposto inflacionário elevou-se de $0,11 \%$ do PIB em 2001 para $0,57 \%$ do PIB em 2002.

A Figura 6 trata do caso do Paraguai. 


\section{FIGURA 6 - PARAGUAI}

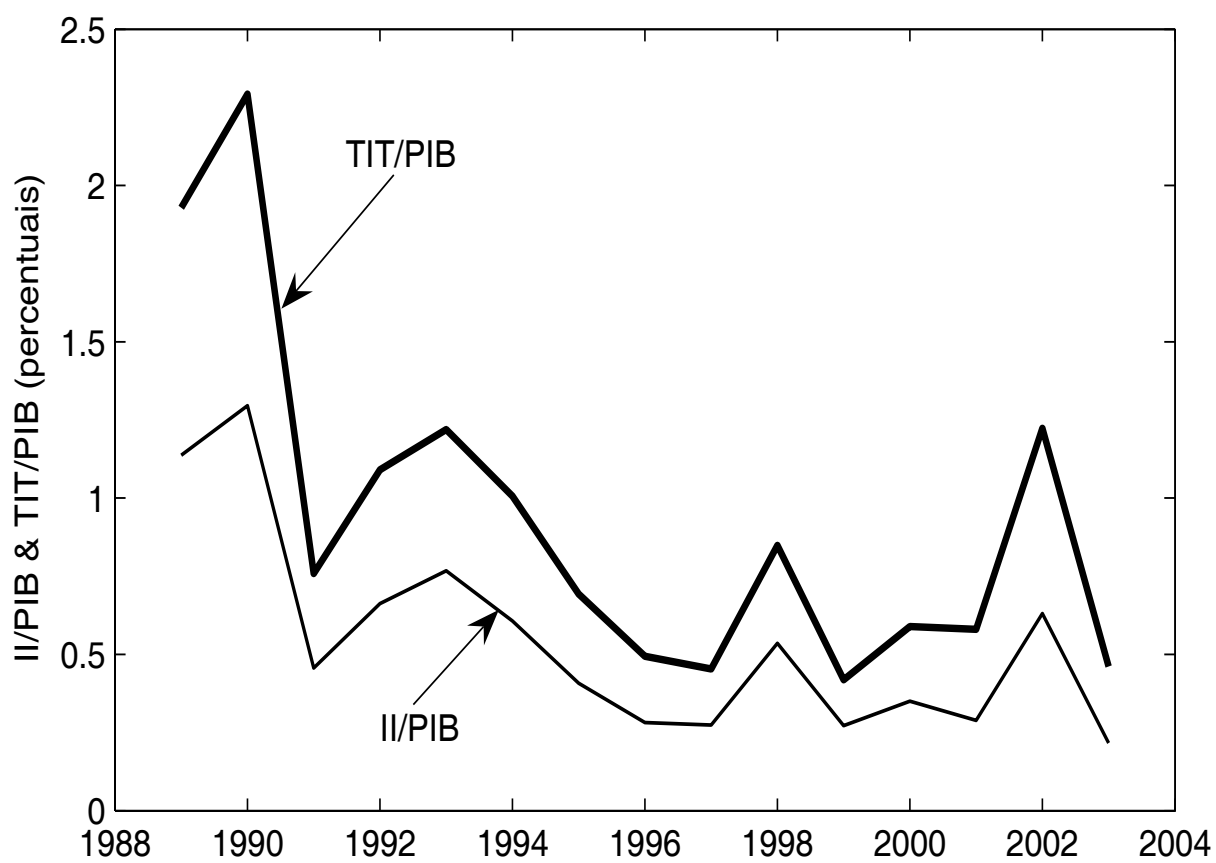

Ao contrário dos demais países do Mercosul já analisados, nos quais o ano de maior inflação não coincide com o ano de maior imposto inflacionário, isto não ocorre no caso do Paraguai. Neste, os níveis mais elevados tanto do imposto inflacionário quanto das transferências inflacionárias totais (respectivamente $1,30 \%$ do PIB e 2,29\% do PIB) ocorreram no ano de 1990, quando se verificou a taxa de inflação mais elevada $(43,11 \%)$. Observa-se, entretanto, que tal resultado não leva em consideração os dados anteriores a 1989.

Excetuando-se os anos de 1998 e 2002, é possível verificar que tanto os valores do imposto inflacionário quanto das transferências inflacionárias totais, do período 1995 a 2003, se situaram abaixo dos menores valores anuais observados (destes mesmos agregados) no período 1989 a 1995. No entanto, o fato que mais chama a atenção é que tanto em 1998 quanto em 2002 a inflação foi praticamente a mesma (em torno de $14,65 \%$ ), enquanto que as transferências inflacionárias totais foram muito mais elevadas em 2002 do que em 1998 (respectivamente 1,22\% do PIB e 0,85\% do PIB). A explicação deste fato está na elevação da demanda por moeda ocorrida em 2002.

Finalmente, a Figura 7 trata do caso dos EUA. 


\section{FIGURA 7 - ESTADOS UNIDOS}

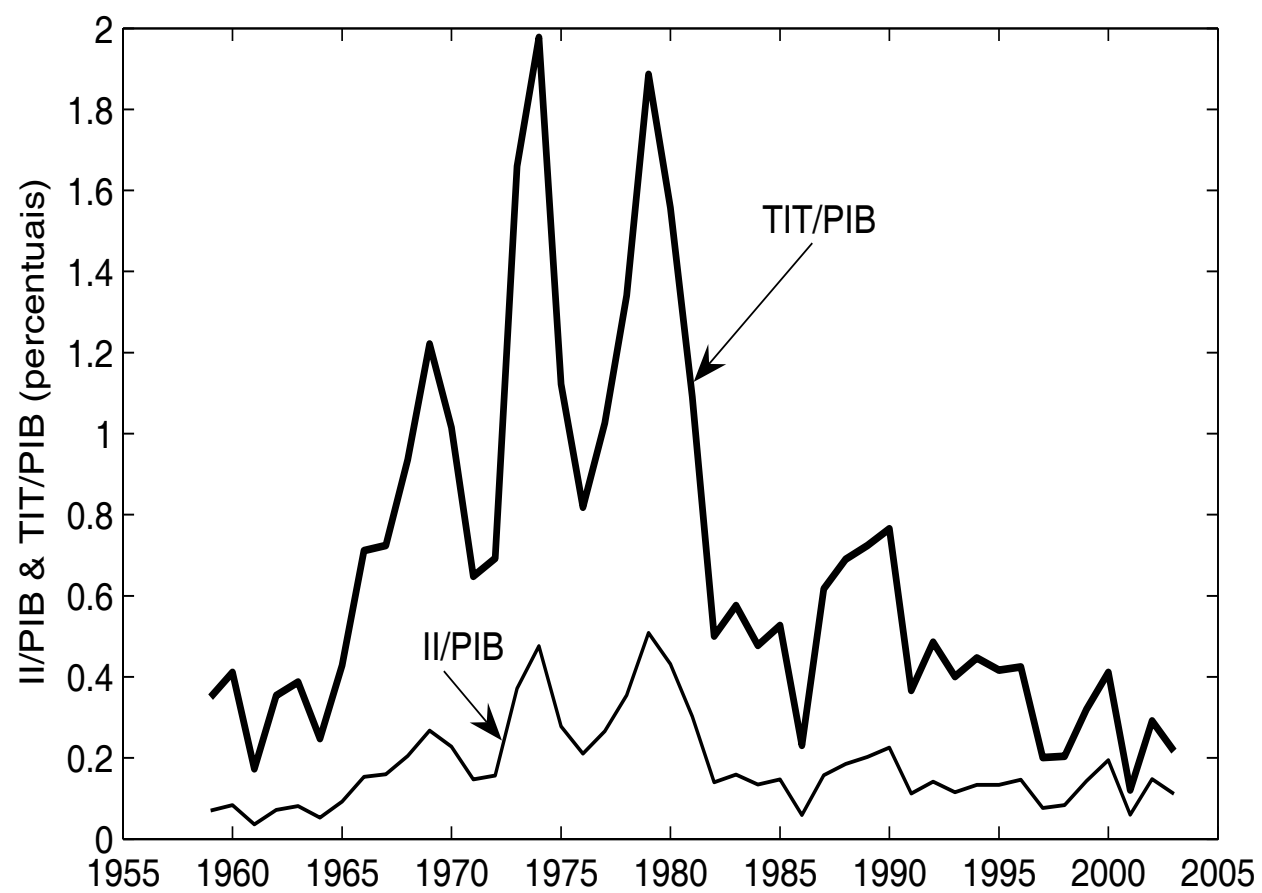

Podemos observar que nos EUA tanto o imposto inflacionário quanto as transferências inflacionárias totais como porcentual do PIB se situaram em níveis bastante inferiores aos verificados nos países do Mercosul. Isto ocorreu devido, principalmente, à baixa inflação registrada. O nível mais elevado do imposto inflacionário como porcentual do PIB $\left(0,51 \%\right.$ do PIB) ocorreu durante a $2^{\text {a }}$ crise do petróleo, no ano de 1979, quando a taxa de inflação alcançou o seu nível mais elevado (13,31\%a.a.). Por outro lado, as transferências inflacionárias totais (1,98\% do PIB) mais elevadas ocorreram durante a $1^{\mathrm{a}}$ crise do petróleo, no ano de 1974, quando a taxa de inflação foi de $12,2 \%$ a. a.. A principal razão a justificar o fato de o nível mais elevado de transferências inflacionárias totais não ter se verificado também no ano de 1979 (quando este agregado correspondeu a $1,89 \%$ do PIB) é a redução da relação entre os meios de pagamento e o PIB, que caiu de 21,54 em 1974 para 17,45 em 1979.

É interessante notar que a partir de 1981 (inclusive) a taxa de inflação ficou em apenas um dígito, o que se refletiu em níveis igualmente reduzidos tanto no imposto inflacionário quanto nas transferências inflacionárias totais. Vale observar, também, que a partir de 1994 as variações nas transferências inflacionárias totais foram bem menos acentuadas do que as variaçóes no imposto inflacionário. 


\section{CONCLUSÕES}

Neste trabalho utilizamos dados relativos à evolução recente, para os países do Mercosul e para os Estados Unidos, de três importantes variáveis macroeconômicas: o imposto inflacionário, as transferências inflacionárias para os bancos comerciais (emissores de depósitos a vista) e a soma destas duas parcelas, dada pelas transferências inflacionárias totais a favor do sistema financeiro gerador de meios de pagamento. Tais variáveis são importantes do ponto de vista macroeconômico, em particular, o ponto abordado na seção introdutória do paper, devido à relação entre imposto inflacionário e finanças públicas, bem como pela relação direta existente quando se admite uma certa classe de funções de transação, entre transferências inflacionárias e custos de bem-estar da inflação.

\section{REFERENCIAS}

Banco Central do Brasil. Várias fontes de dados, incluindo dados no site http://www. bcb.gov.br.

Cysne, Rubens P. Contabilidade com juros reais, déficit público e imposto inflacionário. Pesquisa e Planejamento Econômico, v. 20, n. 1, abril de 1990.

. Imposto inflacionário e transferências inflacionárias. Revista de Economia Politica, v. 14, n. 3, julho-setembro de 1994.

. Divisia index, inflation and welfare. Journal of Money, Credit and Banking, v. 35, n. 2 , p. $221-239,2003$.

Cysne, Rubens P.; Coimbra-Lisboa, Paulo C. Imposto inflacionário e transferências inflacionárias no Brasil: 1947-2003. Revista de Economia Política, v. 26, n. 4, outubro de 2004.

Cysne, Rubens P.; Maldonado, Wilfredo; Monteiro, Paulo K. Inflation and income inequality: a shopping-time aproach. Journal of Development Economics, v. 78, p. $516-528,2005$.

Fundação Getulio Vargas. FGV dados (Fonte de Dados).

Giambiagi, F. Uma proposta de unificação monetária dos países do Mercosul. Ensaio BNDES, abr. 1997.

. Mercosul: por que a unificação monetária faz sentido a longo prazo? Ensaio BNDES, dez. 1999.

Giambiagi, F; Rubini, H. Moeda única e banco central unificado no Mercosul: princípios econômicos e desafios institucionais. Ensaio BNDES, abr. 2003.

Lucas, Robert E. Jr. The welfare costs of inflation. University of Chicago Working Paper. 1993. 
. Inflation and welfare. Econometrica, v. 68, n. 2, p. 247-274, 2000.

International Monetary Fund. International Financial Statistics, v. LVII, n. 7, July 2004.

Ribeiro, M. F. O Euro e as perspectivas de implantação de uma moeda única no Mercosul. Trabalho apresentado no VIII Encuentro Internacional de Derecho de América del Sur, Assunção, 09 a 11 de setembro de 1999.

Simonsen, Mario H.; Cysne, Rubens P. Welfare costs of inflation and interest-bearing deposits. Journal of Money, Credit and Banking, v. 33, n. 1, p. 90-101, 2001. 1995.

. Macroeconomia. $2^{\mathrm{a}}$ ed. Editora Atlas e Editora da Fundação Getulio Vargas, 